\title{
The Community Readiness Initiative in Kugluktuk, Nunavut: The Challenge of Adapting an Indigenous Community-Based Participatory Framework to a Multi-Stakeholder, Government- Designed Project Environment
}

\author{
Chelsea Gabel, Emilie Cameron
}

\begin{abstract}
Aвstract In April 2014, McMaster University and Carleton University collaborated with Kugluktuk, an Inuit community in Nunavut to survey community views on resource development and produce a larger community report. This was part of a Community Readiness Initiative (CRI) piloted by the Canadian Northern Development Agency (CanNor) to assess the socio-economic needs of communities across the North prior to mine development. Kugluktuk is the first of seven communities across Nunavut, the Northwest Territories, and the Yukon to produce their final report. Universities have started to play an important role in developing a 'third mission' whereby researchers are encouraged to collaborate with non-academic organizations. This collaborative approach can include contract research and consulting, as well as informal activities like providing ad hoc advice and networking with practitioners. Working as an academic in this environment can create tensions, but it can also create opportunities to foster and ensure meaningful input and consultation from a variety of stakeholders. This paper focuses in depth on the collaborative nature of the CRI process that began in April 2014 and ended in August 2015 with an emphasis on the community-based participatory research approach that we took. With insights that apply equally well outside of the Kugluktuk context, the approach that we took also provides a useful model for engaging with issues on mining and resource development opportunities.
\end{abstract}

KEYWords Nunavut; resource development; community-based participatory research; collaborative research; capacity building; capacity exchange; academic consultants

The rapid growth of mineral exploration and development activity in Nunavut over the last decade is reshaping the economic, social, and environmental geography of the region. From a low in the early 2000s (after the closure of Nunavut's two operating mines), the mining industry now constitutes a large proportion of the territorial economy. Between 2009 and 2013 , mineral exploration and development expenditures surged from $\$ 187.6$ million to $\$ 426.5$ million. This period also saw the opening of the Agnico-Eagle Ltd. Meadowbank gold mine near Baker Lake, which will soon be succeeded by the company's Meliadine gold mine near Rankin Inlet, now under construction. There are also several major new developments on 
the horizon, such as the Mary River mine on north Baffin Island and the proposed Kiggavik uranium mine near Baker Lake. The Nunavut government predicts that the mining sector alone could create 1500 new jobs for Inuit and eventually account for 12\% of the territorial workforce (Nunavut, Department of Economic Development and Transportation, 2009).

Although there are several advanced exploration sites in the Kitikmeot region of Nunavut, no mines are currently operative within the region. However, Kuglukutkmiut ("people of Kugluktuk" in Inuinnaqtun) have long been involved in the resource extraction sector. Beginning with involvement in mineral exploration through the 1950s and 60s, through to participation in offshore oil and gas exploration in the 1970s, employment at the Lupin Mine south of the community in the 1980s, and involvement in the development and operation of the NWT diamond mines from the 1990s to the present, Kugluktukmiut are familiar with the mining industry. Furthermore, the settlement of the Nunavut Land Claim Agreement included delineation of Inuit surface and subsurface rights within the territory, and established new institutions involved in assessing and licensing proposed mines. Today, Kugluktukmiut work at the diamond mines in the NW'T, are employed at various mining camps in the region, and also work in the various institutions governing extraction in the territory, such as the Nunavut Impact Review Board and the regional Inuit association, the Kitikmeot Inuit Association (KIA). It is anticipated that over the next several years up to eight mines will open in the Kitikmeot region.

In April 2014, McMaster University was approached by the Hamlet of Kugluktuk to engage in a "Community Readiness Initiative" (CRI) being piloted in seven northern communities by the Canadian Northern Development Agency (CanNor). The purpose of the CRI was to "help empower communities to begin to take a more active management role in managing the impacts from resource development" (CanNor, 2013, p.1). McMaster University partnered with Carleton University to undertake a CRI in Kugluktuk and produce a larger community report. The CRI brings together the community of Kugluktuk, non-governmental organizations, land claims organizations, various levels of government, industry, and academic partners. Kugluktuk is the first of seven communities across Nunavut, the Northwest Territories, and the Yukon to produce their final report. All partners have provided input into the CRI process and have worked together to refine the project questions, methodologies, knowledge outcome and dissemination strategies.

Several community members highlighted the importance of engaging in a broader, community-driven discussion about resource development within the context of the CRI process:

I have a ton of nieces and nephews that are going to be just finished high school, or that are going to be looking for work. My biggest worry for them would be are they going to be ready for that? ... Is the life they have now preparing them for what's to come in the future? Are they going to be able to make it through high school? By the time they're done are they going to be ready and are they going to have enough selfconfidence and have that drive and ambition to succeed outside the school? Are they

Engaged Scholar Journal: Community-Engaged Research, Teaching, and Learning 
going to want to work in a mine? (Interview, May 1st, 2014)

It's Inuit land, it's destroying Inuit land when they mine. They can have all the safety practices and all the environmental practices to it, but when they do a mine, you're carving out a big spot out of the land and how do you reclaim that? (Focus Group, April, 29th, 2014)

We need to know what the community needs, so we have a good idea what we need to do in the future to make things work for this community. For one, is this community ready for development, for the type of development that might happen? Are we ready, that's the question. (Interview, April 30th, 2014)

You know, we learn from our elders, we watch our elders, we hear our elders, and what they do we see. What we learn from our elders we pass it down to the youth so that they can learn from us. Because they're thinking if we do this [community readiness initiative] for our community, it would be a good thing so that we could have a healthier Kugluktuk and we would all be working together. (Focus Group, April 29th, 2014)

The university has a history of engaging with and contributing to society (Trencher et al., 2014). Today, academic researchers are strongly encouraged to collaborate with non-academic organizations. This collaborative research includes contract research and consulting, as well as informal activities like providing ad hoc advice and networking with practitioners (Perkmann et al. 2013). The consulting relationship in particular has become an important social function of the university and is one way that researchers can make their knowledge and expertise available to government, public sector organizations, community groups, and industry. For example, in the community of Igloolik, UN partnered with Carleton University in 2009 to undertake a major socio-economic baseline study that could be used to understand the community's status prior to the beginning of major resource development in the region (Kennedy and Abele 2010). The Igloolik Hamlet Council identified a need for more data about the community to establish this baseline and help with local decision-making, and initiated a partnership with researchers from Carleton University, working together to design the project and carry it out. In academic literature, this type of partnership has become known as a "third mission." While the concept of a third mission is somewhat ambiguous, in principle, it refers to diverse activities not covered by the first mission (education) and second mission (research). The third mission includes active university, industry, and government partnerships promoted in public policy. Vorley and Nelles (2008) define the third mission as a "phenomenon, articulated in policy, in which higher education institutions are encouraged to realise their broader socio-economic potential through knowledge exchange and partnerships" (p. 2). Trencher et al. (2014) are critical of the third mission regime arguing that it is too narrow in scope because of its economic focus ( $\mathrm{p}$. 157). Alternatively, we suggest that our approach is more closely situated within what Trencher and his colleagues refer to as an emerging mission, i.e., a large-scale coalition that brings 
together both specialists and non-specialists from academia, industry, government, and civil society. The emerging mission moves beyond the creation of economic development to the creation of social transformations to materialize sustainable development (2014, p. 158). The successful alliance that we describe in this article harnessed the knowledge and expertise from academic, government, industry, community and civic actors with the potential to transform the social structures in Kugluktuk, Nunavut.

The study team assembled for this project included recognized experts in communitybased, participatory research, research in Indigenous communities, survey design and implementation, statistical analysis, and northern resource development, as well as researchers with direct experience conducting research in Kugluktuk and across Nunavut. Furthermore, the study team brought together researchers from two universities, who have access to a network of colleagues with direct experience conducting baseline socio-economic and community-mapping work in northern and Indigenous communities, as well as with experts in mineral development, labour policy and northern policy. Both McMaster University and Carleton University have strong traditions of interdisciplinary collaboration and policyrelevant research. Furthermore, both universities have a strong record of networks that extend beyond the institution. These collaborations take different forms, and occur with a broad range of communities and organizations. Some researchers conduct "community-based or engaged research" (CBR/CER), working closely with community members to create research questions and to build the capacity of community organizations. Other researchers conduct quantitative and/or qualitative analyses which can be used to inform policy development or to help organizations measure the socio-economic impacts of their work. Still other researchers are shaping collaborations which connect research, education, policy and practice.

One of the issues that we encountered early on in the CRI process was that the methodology outlined by the funding agency, CanNor, was not consistent with community priorities for research as conveyed to us by the Advisory Committee, the Project Coordinator, and previous experiences conducting research in the community. ${ }^{1}$ These include an interest in building research capacity among Kugluktukmiut, undertaking culturally-appropriate research, and engaging in a genuinely community-based and participatory project where community members have the opportunity to asess their community on their own terms, for their own purposes, and for the possibility of "owning" the process and the outcome. We thus undertook a lengthy process of negotiating a modified approach to the CRI in Kugluktuk. The purpose of this paper is to focus in depth on the nature, scope and collaborative nature of the CRI process as it unfolded in Kugluktuk, between April 2014 and August 2015, with an emphasis on the methodological approaches that we undertook. The paper will describe the research framework that we drew on as researchers and discuss the benefits and challenges that we encountered while working as academics in a multi-stakeholder environment. This paper also considers how a third or emerging mission can positively reinforce the dynamics of these partnerships through their recursive and reciprocal development (Trencher et al., 2014). The

\footnotetext{
${ }^{1}$ One of the research team members has been involved in research in Kugluktuk since 2005.
} 
model used for this project is one that academics, consultants, and Indigenous communities could draw on or adapt as they embark on similar collaborative processes.

\section{Community Profile of Kugluktuk, Nunavut}

Kugluktuk is located at the confluence of the Coppermine River and the Arctic Ocean (Coronaton Gulf). It is the westernmost community in Nunavut, close to the border of the Northwest Territories, and accessed primarily by air. Formerly known as Coppermine, Kugluktuk has a population of approximately 1,500 people, of which approximately $90 \%$ are Inuit. Inuit in Kugluktuk trace their ancestry from across the circumpolar Arctic but are primarily Inuinnait. Inuinnait have lived in the region for centuries, and settled in the communities of Kugluktuk, Cambridge Bay, Gjoa Haven, Bathurst Inlet, and Holman (Ulukhaktok, NWT) through the latter half of the twentieth century.

Kugluktuk has a medical facility/clinic, a community recreation complex, elementary and secondary schools, a campus of Nunavut Arctic College, several churches, offices of the municipal and territorial government, and a handful of community organizations. Food and other supplies arrive regularly by plane and several times during the summer months by ocean freighter. Food is sold at both the Coop and the Northern Store. The enormous cost of market foods is somewhat offset by wildlife harvesting, a highly important cultural and economic practice in the community.

\section{Partnership and Collaboration}

Overall, the CRI brought together the community of Kugluktuk, non-governmental organizations, land claims organizations, various levels of government, industry, and academic partners. All partners provided input and worked together to refine the project questions, methodologies, knowledge outcomes, and dissemination and communication strategies. The project began with the establishment of a Community Readiness Initiative Advisory Committee. The purpose of the Advisory Committee was to provide direction and oversight for the CRI process, and to play a hands-on role in determining the project questions and research design, along with methodology, knowledge exchange, and communication. The Advisory Committee was instrumental in providing detailed feedback concerning the development of specific research instruments and measures (e.g., the major household survey design), research ethics, and budget management. They also provided strategic advice, offered input and suggestions regarding the broader goals of the project, received and reviewed regular project updates, and addressed potential conflicts when they arose. The researchers worked closely with the Advisory Committee, the Project Coordinator, and a team of university-based researchers and assistants to design and undertake the research that underpinned the final report.

Two key documents governed the management of the project. The first document is a signed agreement between the Hamlet Council and the academic research consultants. The agreement outlines the roles and responsibilities of the research consultants in examining the potential involvement and willingness of the community to participate in resource development occurring near Kugluktuk. The second document is a research agreement between the Advisory 
Committee and the research consultants. The detailed research agreement was put in place to clarify and confirm mutual expectations between the community and the research consultants.

Independent of the governance structure, the researchers, project manager and project coordinator had regular meetings and conference calls to ensure all parts of the project were moving along. Additionally, graduate research assistants were closely integrated into the intellectual work of the project.

\section{Methodology: Overview}

The Kugluktuk CRI Advisory Committee selected our proposal based on its strong participatory and community-driven elements, the range of skills and experiences offered by the research team, and the strength of the existing relationships between one of the researchers and community members developed over the preceding ten years. Once the contract was awarded to the research team, however, it became clear that our approach to the project was inconsistent with the methodological approach and final report template developed by CanNor for the CRI. We thus undertook many weeks of discussion and negotiation to come to agreement with CanNor and the Advisory Committee about the approach we would undertake.

The CanNor approach and template had a number of strengths. It involved multiple research tools (SWOT, PEST, and VSEC analyses; a community skills survey) and was designed to unfold over more than one visit to the community. It involved the Advisory Committee in reviewing and validating existing socio-economic data and participating in the identification of knowledge gaps that might be filled by the CRI process. It was also standardized for use in all seven CRI pilot communities (although the CRI coordinators were cognizant of the need to adapt the CRI approach to specific community needs, and validation of the approach to the CRI process by the community Advisory Committee was part of the early phases of the project phase template). For CanNor's purposes, a single, standardized methodology and report template, applied across the CRI pilot communities, would allow for easy comparison between communities and a more direct evaluation of the pilot program, before unrolling the CRI process across Northern Canada. Such a uniform template would also allow consultants working in more than one community to maximize efficiencies in terms of research design. For individual participating communities, however, standardized comparison with other communities was of less practical value than the identification of community-specific needs and priorities, and the range of other benefits that come from participatory, community-based research design and implementation.

Indeed, although it had strong elements of community consultation embedded in its design, the CRI template was not participatory or community-driven in research design or methodology, which we identified as a significant concern, nor was it explicitly Indigenous or Inuit-specific. As a result, it did not emphasize relationship-building, did not require extensive time in the community, did not emphasize capacity building, did not involve the community in all phases of the research, did not emphasize the four principles of Indigenous ownership, control, access and possession of research results (OCAP), and did not integrate Inuit understandings and approaches to well-being or other culturally-specific values and priorities. 
Overall, the project did not prioritize what Janet Tamalik McGrath (2011) describes as Inuit ways of being-knowing-doing-accounting, a concept she links to Shawn Wilson's writings on Indigenous epistemologies, ontologies, axiologies, and methodologies (Wilson, 2008). Partly owing to these limitations in design, and partly as a result of the mandate of the funding agency, the CRI methodology and report template was also, we felt, too narrowly focused on "mine-readiness" as a matter of education and skills development, rather than as it relates to overall individual, family, and community wellness.

Our challenge was thus to bring as many elements of an Inuit-specific, community-driven, participatory research paradigm as we could to the process, to integrate aspects of capacity building into the project, and to broaden the scope of "mine-readiness" as it was defined in the CRI template, while ensuring that the modified approach would satisfy the multiple stakeholders involved in the process.

The approach we ultimately developed is grounded in a community-based participatory research (CBPR) paradigm, and draws upon both quantitative and qualitative methods. Indigenous peoples are often excluded and disengaged from the research process (Battiste, 2001; Battiste, 2000; Brubacher, 2007; Castellano \& Reading, 2010; Castalleno, 2000; Jackson, 1993; Mitchell \& Baker, 2005; Porsanger, 2004; Smith, 2006; Wilson, 2008). CBPR addresses this by creating bridges between researchers and communities, through the use of shared knowledge and experiences. It further lends itself to the development of culturally appropriate measurement instruments. CBPR also engages communities in generating knowledge about themselves, rather than being simply the objects of study. In this project, for example, community members were trained in various research methods and were directly involved in designing and carrying out focus groups and in conducting the household survey. CBPR promotes community ownership of both process and outcome, enhancing the quantity and the quality of data collected but also the overall sense of community control and ownership over the process. For example, all data and research instruments generated in this process have been passed on to the community for their own use, including follow up studies. Overall, CBPR can result in a deeper understanding of a community's unique circumstances and challenges, a more accurate framework for adapting best practices to the community's needs, and a greater likelihood that findings and recommendations will be implemented.. The core elements of a CBPR approach, we felt, were appropriate for this project given the need to learn from community members about the strengths and weaknesses of their community, and the challenges and opportunities they feel will accompany major resource development.

CBPR methodology is grounded in extensive consultation and relationship-building at the beginning of a project, before any research is carried out, and, ideally, before research questions or methodologies are even identified. In this context, a set of deliverables was expected by the funder within a relatively short timeline, and the CRI governance structure did not allow us to extensively modify the project's overall structure or revisit its core objectives. Nor was this necessarily a community priority: although participants were clear that they wanted the CRI to be as participatory, collaborative, and meaningful as possible, they were also keen to ensure the process worked for (and was legible to) government and industry stakeholders, 
and that the results would be mobilized to create meaningful change. We thus redesigned the methodological template to allow for extensive, open-ended consultation at the start of the project, through one-on-one semi-structured interviews and focus groups and informal household visits. In concert with the existing knowledge and long-term relationships with community members that one of the research team members brought to the project (see Cameron 2011; Cameron 2015), this allowed us to more thoroughly engage the community in the development of an approach that was in line with their concerns and priorities.

Our overall approach to the project involved a) grounding the project in an Inuit model of wellness and Inuit models of consultation; b) introducing extensive front-end consultation through focus groups with a range of stakeholders (youth, elders, women, men, mine workers, industry representatives and others) and semi-structured interviews with community leaders, organizations, industry, government, and other stakeholders (with expertise in health, education, housing, criminal justice, wildlife, economic development, culture, and other key issues); c) increasing the involvement of the Advisory Committee in research design; d) redesigning and expanding the CRI community skills survey template in order to deliver a major omnibus survey that was consistent with existing government and community baseline socio-economic survey instruments; e) changing the assigned "Valued Socio-economic Components" (VSECs) to better reflect Inuit frameworks of wellness and Inuit cultural priorities; f) local employment and capacity building (training of community-based surveyors, training in research methods, training in SWOT, i.e., Strength, Weaknesses, Opportunities \& Threats and PEST, i.e., Political, Economic, Social and Technological analysis); g) expanding the conceptualization of "minereadiness" underpinning the project to include the range of social determinants that impact wellness in the community, in addition to education and skills training; and h) the use of social media.

\section{Methodology: Project Phases}

The research and report writing phases of the CRI unfolded over 16 months, culminating in the submission of a final CRI report. Below, we describe the approach and project phases that we undertook as part of the CRI process in greater detail.

\section{Preliminary Meetings, Relationship-Building, and Preliminary Data Collection (April/May 2014)}

Our first step was to undertake an initial fact-finding meeting to Kugluktuk where we introduced ourselves and CRI at a community feast. 

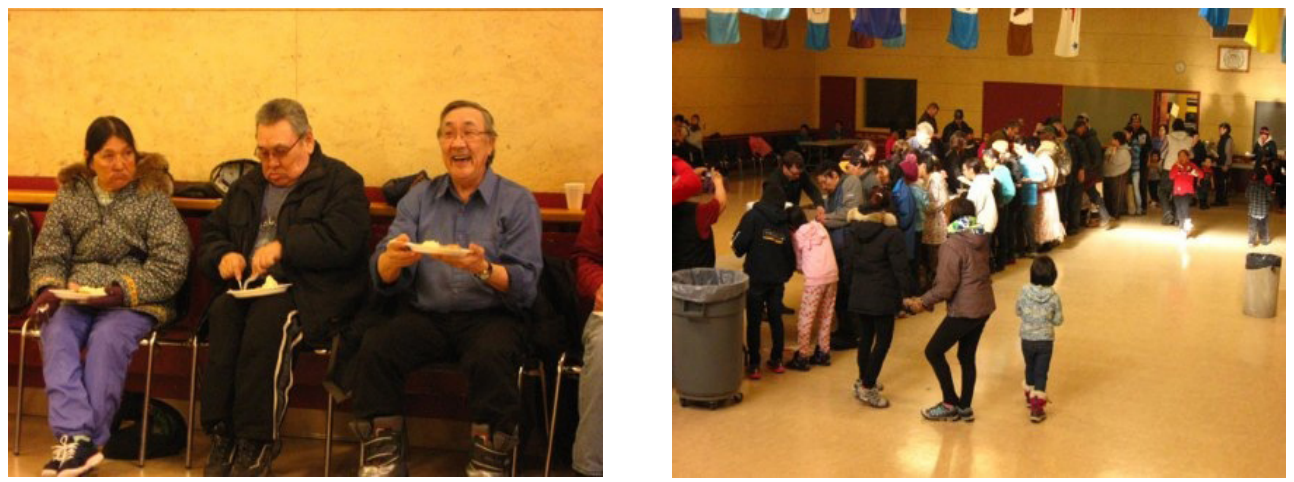

Figures 1 and 2: Community feast to kick off the CRI Initiative (Courtesy of CRI Facebook page)

Following the feast, we held a number of discussions with a range of representatives and key stakeholders about their interests and the overall scope of the project. We also conducted a preliminary mapping of community assets and concerns at the community level, household level, and individual level by way of focus groups with women, men, elders, youth, mine workers, hunters and others as identified by the advisory committee. Additionally, we conducted semistructured interviews with a number of community members including medical staff, RCMP, teachers, housing, economic development officers, and others. Interviews and focus groups were also carried out in Yellowknife with government and industry partners, to further ground our understanding of the issues and various stakeholder priorities.

The semi-structured interview and focus group format is beneficial because it encourages interaction between community members and helps to generate conversation and identify group priorities and norms. We felt this methodology allowed for more culturally appropriate, inclusive, and open-ended conversations at the community level.

A Facebook page for the Community Readiness Initiative was designed and launched by the Project Coordinator in May 2014 and was an important venue for sharing information about the project, recruiting participants, and maintaining community interest and momentum. During this phase we also conducted a thorough review of the academic and grey literature relevant to the project, as well as existing socioeconomic data.

\section{Development of Inuit-specific Approach to the Project}

Community members emphasized the importance of ensuring that the Kugluktuk CRI process drew, as much as possible, on Inuit frameworks of knowledge and practice, and we aimed, as much as possible, to ground the CRI in Inuit frameworks of knowledge production, decision-making, and consultation. Jackie's Price's (2007) extensive study of Inuit governance highlights the myriad ways Inuit governance systems are undermined in government, academic, and industry processes, and proposes a "Kitchen Consultation Model" of decision-making grounded in Inuit values, practices, ways of knowing, and relationships. Although the context, timeline, and governance structure of the CRI did not allow for a fully robust "Kitchen 
Consultation Model" to be undertaken, we aimed to integrate some of the key principles of this approach, including placing the Advisory Committee at the core of decision-making (moving decision making power away from outsiders and/or government and into the hands of community leaders); emphasizing an open-ended, ongoing, informal discussion at the household level; and involving community members in carrying out their own research as part of the CRI (several focus groups that informed the final report, for example, were designed, carried out, and reported on exclusively by community members, and none of the research team was present).

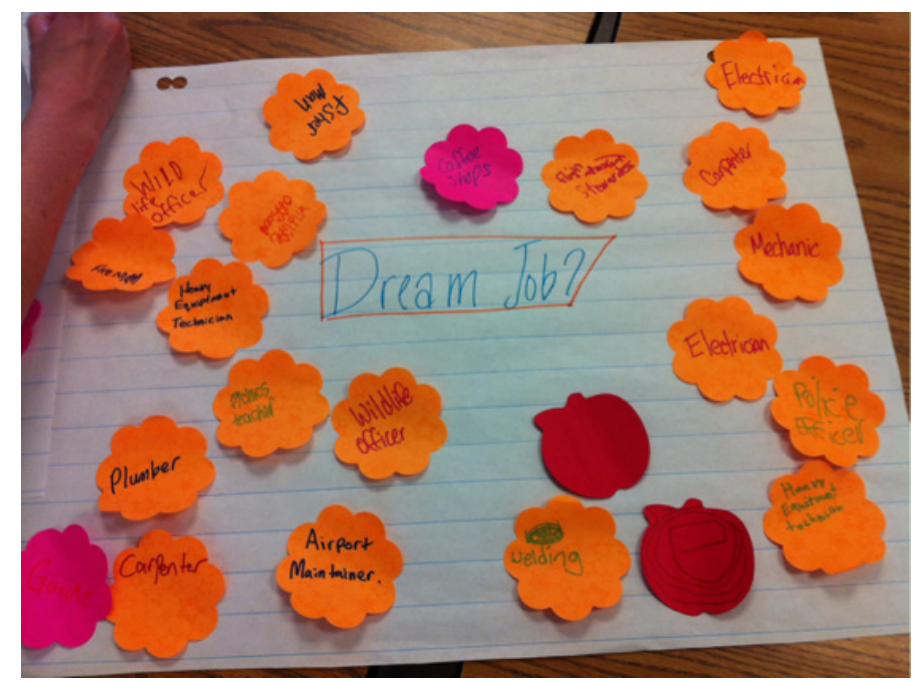

Figure 3: Youth Focus Group and Brainstorming Session

The initial request for proposals outlined a methodological approach involving the identification of Valued Socio-economic Components (VSECs). VSECs are a standard approach to socio-economic study within the environmental assessment industry, including submissions to the Nunavut Impact Review Board, and are intended to identify the characteristics that collectively make up what is of value at the community level. Although the VSEC approach has its strengths, we proposed an alternative methodology. We proposed grounding our understanding of what is "valued" by Kugluktukmiut in an Inuit framework of wellness, and proposed modifying the assigned VSEC elements to reflect more fully local understandings of the foundations of individual, family, and community well-being. In so doing, we also committed to working with the Project Coordinator to ensure that the final report would link these revised components to the standard VSECs, to promote maximum legibility and uptake of the report and its recommendations.

We grounded our understanding of what matters to Kugluktukmiut in the inuuqatigiingniq, inuuhiqattiarniq, and niqiqainnarniq (peoplehood, personhood, livelihood) model articulated by Janet Tamalik McGrath (2011). Developed in conversation with the late, highly respected elder Aupilaarjuk, McGrath explains that well-being, in an Inuit framework, is based on the 
interrelation of collective and individual well-being, and grounded in collective and individual capacities to provide food and livelihood. Peoplehood, personhood, and livelihood are interdependent: all must be strong and valued for overall well-being. ${ }^{2}$

One of the reasons the Advisory Committee preferred the inuuqatigiingniq, inuuhiqattiarniq, and niqiqainnarniq model is that it makes a strong connection between waged work and Inuit values of procuring and sharing food. As we describe in the CRI Final report (Cameron and Gabel 2015), niqiqainnarniq (livelihood), in an Inuit framework, is not reducible to either waged work or the ability to eat (niqiqainnarniq translates as "always having meat"). Although food is, of course, of fundamental importance to well-being, and waged work plays an important role in Inuit capacities to provide their families with food, niqiqainnarniq also refers to cherished skills, relationships, and practices that build individual and collective wellbeing overall. What matters about "always having meat" is not just that people have their nutritional needs met, but rather that people are grounded in the skills and relationships that enable them to contribute to their community, provide for themselves and others, practice skills, nurture relationships with the land, and promote overall social, cultural, and economic well-being. This offers a very different conceptualization of the importance of both waged work and food provisioning in Inuit communities than the model employed in most government programs and assessment processes.

What difference does it make to assess well-being in this way? As many local mine workers and their families emphasized, part of their pride in maintaining jobs at the mines was related to their capacity to purchase snow machines, ATVs, and other resources necessary to harvest wildlife, not just for their own use, but also to contribute to extended family and community networks. The inuuqatigiingniq, inuuhiqattiarniq, and niqiqainnarniq model also highlights broader Inuit values about the land, that are not well encapsulated by Qablunaaq (non-Inuit) understandings of the environmental impacts of mining. As one community member noted regarding the risks posed to the land from mining:

If say 5,10 mines pop up just around Kugluktuk, then how is the community going to be affected? Will we be able to have clean drinking water? Or clean fish? Or healthy caribou? Or will the air be polluted? Those would probably be my biggest concerns. (Interview, May 1st, 2014)

Within Inuit frameworks, it is clear that what is at stake in discussions of the land is not just ecological integrity, but also a fundamental set of relationships that enable social, cultural, economic, physical, spiritual, and collective well-being. Traditional VSECs identified by government for this project included components such as religion, spirituality, crime and fate control, as well as several other characteristics. Many of the VSECs did not adequately capture

\footnotetext{
2 McGrath notes the resonance between "Aupilaarjuk's triad" of inuuqatigiingniq, inuu-hiqattiarniq, and niqiqainnarniq and the IQ Task Force's emphasis on the foundational importance of four primary relationships: relationship with the land, with family, with inner spirit, and with social grouping (IQ Task Force, 2002). The two models are comparable and both underpin the Kugluktuk CRI's overall approach to assessing and characterizing the well-being of Kugluktukmiut.
} 
Inuit values or the specific concerns of the community. Drawing on the inuuqatigiingniq, inuuhiqattiarniq, and niqiqainnarniq model, we modified the approach and identified eight components of wellness in Kugluktuk, which we described in detail in the final report. These eight components include Land and Environment, Social Relations (including Crime) Physical and Mental Health and Wellness (including Food Security), Education and Training, Employment and Economic Activity, Community Services and Infrastructure, Cultural and Spiritual Well-Being and Self-Determination. Each was assessed more fully in the following phases of the project, and ultimately recommendations were developed to support each component.

\section{Development and Implementation of Household Survey (June-August 2014)}

The CRI template included a community skills survey designed to gather information about the education and skills of community members, as well as some basic demographic information and information about harvesting practices. We opted, instead, to carry out a major omnibus household survey that would provide substantial baseline socio-economic information as well as pose questions about broader social, economic, political, environmental, cultural, and health issues. The survey instrument was designed to be consistent with existing government and community household surveys (it drew on the survey instrument used in the Nunavut Bureau of Statistics' 2001 Nunavut Household Survey and a socio-economic baseline survey undertaken in Igloolik, NU, in 2009) to promote comparability with existing and future surveys.

The community was instrumental in shaping survey design and in implementing the survey itself. The overall focus of the household survey was agreed upon through meetings with the CRI Project Coordinator and the Advisory Committee in June 2014. Final approval of the survey instrument was granted by the Advisory Committee in July 2014. The Project Coordinator tested the survey in early August 2014 and four community based surveyors were hired and trained to carry out the survey. The research team and community-based surveyors surveyed every day from August 15 to August 27, 2014, primarily surveying in peoples' homes, but also offering community members the option to respond to the survey at the Hamlet office or another location of their choosing. Awareness about the survey (and the larger CRI process) was boosted by radio announcements, signs in key community venues, and the Facebook page, which had significant traffic during this time. Everyone involved worked very hard to maximize the response rate, and as a result 416 surveys were completed, representing over $40 \%$ of the adult population. This is a significant response rate and allowed for robust claims to be made about the resulting data, including disaggregation of the results by Inuit and non Inuit residents of the community. The survey findings significantly informed the CRI process and report. The benefits of conducting a survey specifically designed for the community, and drawing on existing territorial and community survey templates, is that: a) we asked questions of particular relevance and importance to the community in addition to the questions usually asked in household surveys; b) community-specific questions enhanced community "buy-in" to the survey, which promoted a higher response rate; c) the survey can be replicated in future years to measure change over time. Furthermore, because the Kugluktuk Household Survey

Engaged Scholar Journal: Community-Engaged Research, Teaching, and Learning 
was an omnibus survey - a survey which contains questions about a range of topics - we can better understand the relation between different aspects of the lives of Kugluktukmiut. For example:

- The KHS showed that approximately $50 \%$ of adult Inuit are dissatisfied with the health services available to them, and $43 \%$ of adult Inuit are dissatisfied with the mental health services available.

- The KHS allowed us to note that persons who had worked for wages in the year prior to the survey were more likely to self-report their harvesting activity as Active (as opposed to Occasional or Rarely/Never/Do Not Know) than those who had not worked for wages in the year prior to the survey.

Graduate students were hired and trained to input all survey data into the Statistical Package for the Social Sciences (SPSS) in September and October of 2014. In January and February 2015 preliminary statistical analysis was undertaken and shared with the CRI Project Coordinator and further statistical queries were identified. A final statistical report on the survey findings was submitted in May 2015. Results of the household survey directly informed the community readiness process in Kugluktuk. The research team also prepared a separate, stand-alone survey report for the community so that it can be put to use in other settings, including for ongoing monitoring or for use as a submission in various environmental assessment and other decision-making processes.

A BBQ was held to thank the community for participating in the survey and it was successful with over 220 people attending.

\section{Capacity Building and Training in Research Methods (August 2014 - February 2015)}

As researchers, we felt that training, capacity building and capacity exchange were essential components of our approach to the project. Four community members were recruited and trained in community survey techniques in August 2014. They were instrumental in conducting the household survey. Additionally, the research team subcontracted two independent researchers to run a two-day workshop that enabled community members to learn about Indigenous and social research methods used by universities and consultants and learn how to use those methods themselves. In particular, community members were familiarized with several of the tools typically used in government and industry consulting processes, including the CRI. When we redesigned the project methodology, we agreed to package our findings in ways that would be legible to government and industry, particularly the SWOT method. A SWOT analysis refers to Strengths, Weaknesses, Opportunities, and Threats. We trained community members in the SWOT method. We also familiarized workshop participants with the "PEST" approach, which refers to Political, Economic, Social and Technological analysis. SWOT and PEST approaches are traditionally used by consultants, business and government to explore internal and external factors in order to decide future directions and actions (Van 
Wijngaarden, Scholten, \& van Wijk, 2012). Rather than simply apply these methods in the community, we thought that it would be useful to have a workshop to inform community members about these methods and their uses, and modify these methods in a way that fits the community. As a result, participants worked together to redesign the SWOT and PEST methods for use in Kugluktuk, and practiced applying them. The Project Coordinator attended the training session and the research team supported her

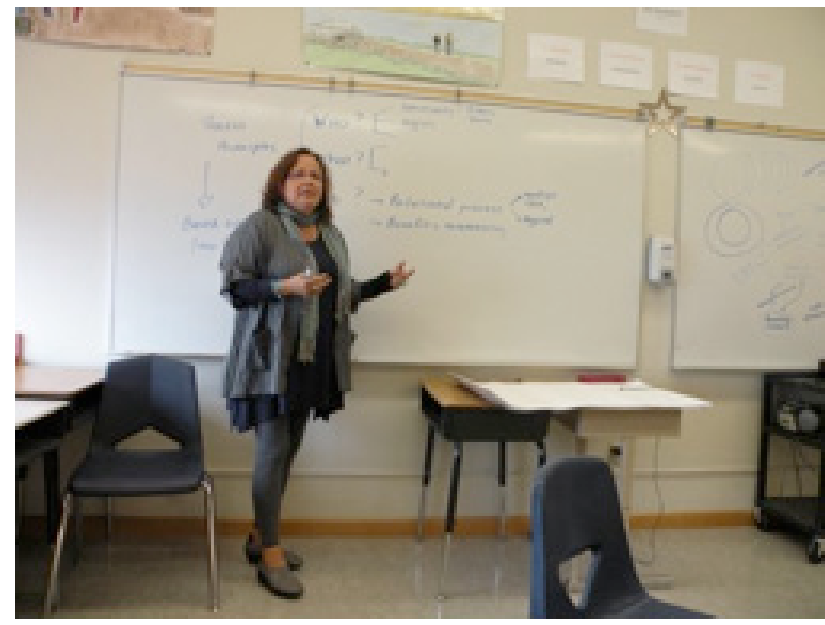

Figure 5: Dr. Bernice Downey (McMaster University) leading the SWOT and PEST Community Workshop as she undertook SWOT and PEST focus groups on her own in the fall of 2014 and winter of 2015 with various community groups. The Project Coordinator provided reports and transcripts from the workshops which informed the overall report findings.

\section{Analysis, Knowledge Dissemination, Mobilization, and Reporting (May 2014 - July 2015)}

The phases described above resulted in a rich repository of qualitative and quantitative data. The focus group and interview transcripts were analyzed using Nvivo 10 qualitative data analysis software. Nvivo is a useful tool in assisting researchers to identify and code themes from large data sets. The in-depth nature of the interviews and the wide range of topics discussed made Nvivo especially useful for the CRI project. In analyzing the data, a grounded approach was taken in which the themes and coding categories were developed primarily from the content of each focus group and interview. This inductive method to developing the thematic analysis gives prominence to the voices of the interviewees, allowing for the self-described needs and interests of the community to be accurately reflected in the coding results. Qualitative findings were combined with the household survey data and other available data and reports to develop a rich, 133-page report covering community perspectives, needs, strengths, weaknesses, and priorities for moving forward. In January 2015 we hosted a threeday meeting in Ottawa where preliminary findings were shared and discussed with the Project Coordinator and our core analysis was undertaken. These meetings helped refine priorities for the report, sharpened analysis of key findings, and ensured that the CRI process was in keeping with community priorities and interests.

A draft report was prepared in May 2015 combining comprehensive discussion of findings, with links to preliminary community mapping findings. Additional focus groups, interviews, and one-on-one meetings were held in the community in late May 2015 to discuss the draft report, refine key findings, and provide input for finalizing the community map. A roundtable 
meeting of stakeholders with interests in the CRI process was also held in Kugluktuk on May 27, 2015 to present the draft report, validate key findings, and gather input before finalizing the community map. The final report compiled and synthesized this feedback and was submitted in July 2015.

To protect the privacy of the people who answered the questionnaires, the original survey information is stored securely at one of the host universities. It will be released only to researchers identified by the Hamlet for the purpose of conducting a follow up study. An anonymized copy of the survey database was provided to the Hamlet, however, to allow the Hamlet or other parties to query the results in the future. As per our research agreement, the researchers are also able to publish academic articles based upon what we have learned in Kugluktuk.

Knowledge was also disseminated throughout the life of the project over the Facebook designed and launched by the Project Coordinator in May 2014. It was an important venue for sharing information about the project, recruiting participants, and maintaining community interest and momentum.

\section{Implementation and Legacy}

Kugluktukmiut emphasized throughout the CRI process that implementation of the project findings was of primary importance. Concern that the CRI report would simply "sit on a shelf" was expressed by many community members. Implementation and long-term change requires community ownership and involvement in every stage of the project. We therefore recommended that funding for a community-based project coordinator extend over the six months following submission of the final report. The task of the project coordinator for this phase of the project would have been to: a) coordinate a three-day meeting in Kugluktuk bringing together stakeholders from across the community to discuss the final report, prioritize recommendations, and take ownership of specific initiatives; b) move forward with priority recommendations, in coordination with relevant partners; and c) help secure funding and other resources to support longer-term objectives and priorities identified through the CRI process. To our knowledge, this recommendation was not taken up, but the Project Coordinator was retained for a short period following submission of the report, and there have been some follow-up actions in the community related to the CRI.

Project partners are currently investigating how best to move forward with the implementation of the fifty-two proposed recommendations that resulted from the final report. The recommendations focus on actionable steps that can be taken at the community level to address issues facing the community. There is widespread consensus in the community that the first priority action is to address mental health and wellness in the community. Currently, community stakeholders are looking at implementing some of the report recommendations and are in the process of developing a proposal for a series of mental health focused workshops. Without significant investment and improvement in individual and community mental health status, the community feels it simply cannot take advantage of resource development. The report also contains recommendations that have broad community support and could be 
implemented quickly. These include a program to facilitate criminal record suspensions and programs to improve financial literacy within the community. These are also being investigated by community partners for implementation in the near future.

To support ongoing monitoring, planning, and funding application work in the community, we have provided the community with an electronic database of key project files, including research instruments and results. An anonymized copy of the survey database was also provided to allow the Hamlet or other parties to query the results in the future.

\section{Discussion}

The collaborative experience and the methodological approach that we describe above reflects a strong commitment to Indigenous individuals, communities and organizations. Having participated in extensive consultations, discussions, surveys, interviews and focus groups in Kugluktuk on the impacts of mining and resource development, we gained an awareness of the dynamics of community, government, and industry relations and became increasingly sensitive to the challenges that are faced by Indigenous and non-Indigenous stakeholders in community, government, and industry consultations. While there were several occasions when we left a government or an industry meeting feeling that we were approaching the issue from a very different place, all stakeholders were genuinely committed to making the CRI work, and we were often inspired by individuals in all sectors who had committed themselves to such a complex initiative.

One of the biggest challenges of this project was to adapt the existing methodological and final report template provided by CanNor to be more participatory, community-driven, and Inuit-focused, and to ensure that capacity building and community ownership were emphasized. We also wanted to ensure that the data generated throughout the project would be meaningful and useful, that the community would have ownership over all research tools and findings, and that inquiry into the broader social determinants of wellness, as understood by Inuit, would underpin the project. Ultimately, all parties were very pleased with the outcome, and the final report has been praised by industry, government, and community leaders for its rigor, usefulness, and detailed findings. This was achieved through continuous communication between the different partners involved in the CRI and us, and by putting extra time and resources into ensuring that the report was legible and accessible to all involved.

It is important to note that our approach to the CRI process was successful in part because we also had at our disposal a number of resources including graduate student support, large networks of experts in the field and access to other consultants. Because the money that went into this project was earmarked for community re-distribution and not the researchers themselves, coming in under budget was not the driving factor. Realistically, our approach would not be feasible for consultants but could be adapted to make their own practice more community-based and culturally-appropriate.

The process was also successful, we feel, because we understood and respected the reasons underpinning the original design of the CRI. CanNor's approach has rigor and was based on many months of planning and the experience of senior staff with long term connections with 
northern communities. It was also consistent with processes that a number of governments and organizations have undertaken, and we understood the importance of ensuring that the project resulted in findings that were legible to government decision-makers and other stakeholders, and that allowed for some comparability with other pilot communities. Indeed, that is one of the main reasons that we designed the survey to be consistent with past Nunavut household surveys and other community-driven baseline studies in the territory. Comparability over time and space can be an important tool in planning and monitoring socio-economic issues, and we wanted to ensure that the baseline study be of use beyond the confines of the CRI.

Although the standard CRI template had many merits, as researchers we did not feel that it was possible to follow the government template as it was laid out and also undertake a community-based, culturally-sensitive, and participatory project in Kugluktuk that would result in increased capacity and significant community ownership of findings. In fact, our fear was that if we carried out the project in exactly the way it was proposed, we would risk reproducing and exacerbating exactly what Indigenous northerners have repeatedly raised as a major concern: they are tired of being researched by outside consultants and academics for the purposes of reports and findings that have no meaning to them, and that are used to make decisions on their behalf. Or, as many Kugluktukmiut repeatedly emphasized, they are tired of participating in studies that result in reports that "sit on the shelf" and are never implemented. This phenomenon is exacerbated when there is a lack of community leadership and buyin, and we thus aimed to promote as much community ownership of the entire process as possible.

As a result, we included elements that we believed added a great deal of value, including the implementation and development of a major household survey that was agreed upon through multiple meetings and discussions with the CRI Project Coordinator and the Advisory Committee. Additionally, we prepared a separate, stand-alone survey report for the community so that it can be put to use in other settings, including as a submission in various environmental assessment and other decision-making processes. We provided training for the Project Coordinator and other community members in SWOT, PEST, and Community Needs Assessment tools, and the facilitation of a workshop whereby community members had the opportunity to engage with the VSEC model and determine culturally-appropriate, community-specific metrics and protocols that make sense to them. We involved highlyrespected cultural consultants in this process who are recognized experts in communitybased participatory research method, Indigenous methodologies and in Inuit-specific forms of knowledge production. And, we grounded the project, as much as possible, within Inuit frameworks of knowledge.

Academics who work as both community advocates and consultants are challenged with the task of navigating these different worldviews. The balance of power and authority becomes altered because the researcher is a representative of an academic institution whose desired outcome of research is to benefit a community rather than to benefit the academy, government, or industry. On the other hand, the researchers in this context are also required to take on the role of consultant whereby partnering with government and industry and adhering 
to their procedures and processes is expected. A further challenge for academics taking on this type of role is having the ability to navigate existing tenure and promotion structures in academia which tend to value the legitimization of new knowledge (through publications) and its potential for production (through research grants and funding). Building long term societal relationships, which are both important yet complex, is at odds with an academic career progression that values a constant stream of research outputs (Trencher et al., 2014, p. 170). As a result, the university is in a unique position to place more value on collaborative partnerships and propose an alternative academic model of innovation and societal engagement more aligned to the needs of the 21 st century.

\section{Conclusion}

A number of stakeholders across diverse sectors in the north share a deep interest in issues of mining and major mineral development, including a range of government and nongovernmental organizations, industry, community groups, and other stakeholders. The Community Readiness Initiative that took place in Kugkuktuk, Nunavut, provides a window into the complex challenges of academic engagement and collaborative work in a multistakeholder environment. With insights that apply equally well outside of the Kugluktuk context, this approach also provides both a quantitative and qualitative model for engaging with issues on mining and resource development opportunities. Indigenous communities that choose to work with consultants and/or academics outside of their community could draw on and/or adapt this approach as a way of fostering and ensuring meaningful input and consultation from different stakeholders.

The approach described above was the right one for this type of initiative. A collaborative, participatory, and Inuit-focused approach to the CRI ensured that the project engaged and was accessible to all audiences, and promoted the development of intellectual, cultural, social, economic and policy-related benefits to a wide range of stakeholders. These benefits transcend what could be delivered by any one individual or partner. Ultimately, despite its challenges, we hope the CRI supports the community of Kugluktuk to realize their vision of engaging with the mining industry as a strong people, as a community of healthy individuals and families, in ways that support sustainable and satisfying livelihoods, and in ways that ensure the long term well-being of the land and peoples' relationships with the land. 


\section{About the Authors}

Emilie Cameron is an Associate Professor in the Department of Geography and Environmental Studies at Carleton University in Ottawa, Ontario. Her research focuses on mineral exploration and mine development in the Canadian Arctic, examining how mining interweaves with comprehensive land claim agreements, environmental assessment institutions, self-determination movements, and histories of colonial knowledge production.

Chelsea Gabel (corresponding author) is Métis from Rivers, Manitoba. She is an Assistant Professor in the Department of Health, Aging and Society and the Indigenous Studies Program at McMaster University in Hamilton, Ontario. Her research discusses and evaluates processes and institutional structures that influence relationships between Indigenous communities and government in the development, implementation and evaluation of health policy. Email: gabelc@mcmaster.ca

\section{References}

Battiste, M. (2001). Decolonizing research: The quest for ethical guidelines for research involving Indigenous populations. In G. Alfredsson \& M. Stavropoulou (eds.), Justice pending: Indigenous peoples and other good causes: essays in honour of Erica-Irene Daes (pp. 33-44). New York: Martinus Nijhoff Publishers.

Battiste, M. (2000). Reclaiming Indigenous voice and vision. Vancouver: University of British Columbia Press.

Brubacher, D. (2007). Second report on First Nation-held forest tenures in Canada. National Aboriginal Forestry Association.

Cameron, E. (2015). Far off metal river: Inuit lands, settler stories, and the making of the contemporary arctic. Vancouver: UBC Press.

Cameron, E. (2011). Copper stories: Imaginative geographies and material orderings of the central Canadian Arctic. In A. Baldwin, L. Cameron, and A. Kobayashi (eds.), Rethinking the great white north: Race, nature and the historical geographies of whiteness in Canada (pp. 169-190). Vancouver: UBC Press.

CanNor. (2013). Community readiness. Retrieved from http://www.cannor.gc.ca/eng/1368817398699/ 1368817423354

Castellano, M., \& Reading, J. (2010). Policy writing as dialogue: Drafting an aboriginal chapter for Canada's tri-council policy statement: Ethical conduct for research involving humans. The International Indigenous Policy Journal, 1(2), 1-18.

Castellano, M. (2000). Updating aboriginal traditions of knowledge. In G.J. Dei, B.L. Hall, \& D.G. Rosenberg (eds.), Indigenous knowledges in global context: Multiple readings of our world (pp. 21-36). Toronto: OISE/University of Toronto Press. 
Inuit Qaujimajatuqangit (IQ) Task Force (2002). The first annual report of the Innit Qanjimajatuqanginnut (IQ) task force. Iqaluit: Government of Nunavut.

Jackson, T. (1993). A way of working: Participatory research and the Aboriginal movement in Canada. In P. Park, M. Brydon-Miller, B. Hall, \& T. Jackson (eds.) Voices of change: participatory research in the United States and Canada. London: Bergin and Garvey.

Kennedy, S. and Abele, F. (2010). Igloolik socioecononomic baseline study 2009-2010. Prepared for the Hamlet of Igloolik.

McGrath, JT. (2011). Isumaksaqsiurutigijakka: Conversations with Aupilaarjuk towards a theory of Inuktitut knowledge renewal. Doctoral dissertation). Retrieved from Carleton University.

Mitchell, T.L., \& Baker, E. (2009). Community building vs. career building research: The challenges, risks, and responsibilities of conducting participatory cancer research with aboriginal communities. In J. Bally (eds.) Cancer on the margins: Method and meaning in participatory research (pp.56-74). Toronto: University of Toronto Press.

Nunavut, Department of Economic Development and Transportation (2009). Parnautit: A foundation for the future: Mineral exploration and mining strategy. Iqaluit: Government of Nunavut.

Porsanger, J. (2004). An essay about Indigenous methodology. Nordlit, 8(1), 105-120.

Price, Jackie. (2007). Tukisivallialiqtakea: The things I have now begun to understand. Inuit governance, Nunavut, and the kitchen consultation model. Unpublished master's thesis, Department of Human and Social Development, University of Victoria.

Smith, L.T. (1999). Decolonizing methodologies: Research and Indigenous Peoples. London: Zed Books.

Trencher, G., Yarime, M., McKormick, C., Doll, N.H., Kraines, S. (2014). Beyond the third mission: Exploring the emerging university function of co-creation for sustainability. Science and Public Policy, 41(2), 151-179.

Van Wijngaarden, J. D. H., Scholten, G. R. M. and van Wijk, K. P. (2012). Strategic analysis for health care organizations: The suitability of the SWOT-analysis. International Journal of Health Planning Management, 27(1), 34-49.

Vorley, T. \& Nelles, J. (2008) '(Re) Conceptualising the academy: Institutional development of and beyond the third mission', Higher Education Management and Policy, 20(3), 1-17.

Wilson, S. (2008). Research is ceremony: Indigenous research methods. Black Point, Nova Scotia: Fernwood Publishing. 